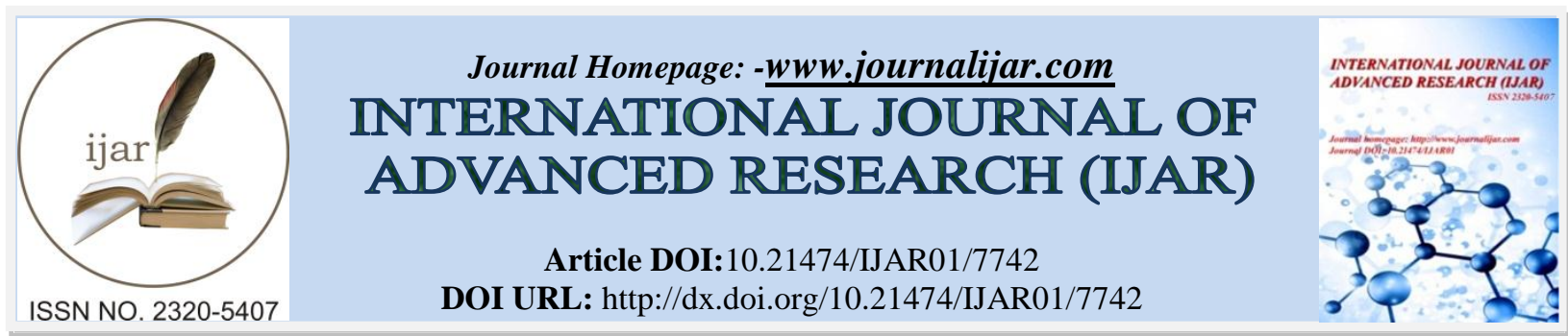

RESEARCH ARTICLE

\title{
OUTCOME ANALYSIS FOLLOWING TIBIAL ANGIOPLASTY IN PATIENTS WITH CRITICAL LIMB ISCHEMIA- A SINGLE CENTRE EXPERIENCE.
}

\author{
Dr. M. Bakthavatchalam, MS., MCh ${ }^{1}$, Dr. Sasikumar Krishnan, MS, $\mathrm{MCh}^{2}$, and Dr. Deepak George John ${ }^{3}$. \\ 1. Professor, Department of Vascular Surgery, TNGMSSH, Chennai-02, \\ 2. Assistant Professor, Department of Vascular Surgery, TNGMSSH, Chennai-02, \\ 3. Resident, Institute of Vascular Surgery, MMC, RGGGH, Chennai-03.
}

\section{Manuscript Info}

Manuscript History

Received: 23 July 2018

Final Accepted: 29 August 2018

Published: September 2018

Keywords:-

Critical limb ischemia, infra popliteal, angioplasty

\begin{abstract}
Background:Peripheral arterial occlusive disease (PAD) affects a major proportion of our elderly population and is a main cause for limb loss and morbidity. PAD can be managed by conservative, surgical and endovascular methods. Percutaneous transluminal angioplasty with or without stenting has become a recognized method, which is increasingly used in treatment of arterial occlusive disease.

Aim:Our study aimed to analyse the outcome following endovascular intervention in patints with infrapopliteal lesions.

Methods: The study included 29 patients ( 21 men and 8 females; mean age 62 years, range 38-84) with CLI (class 4 to 6 according to Rutherford). The primary study endpoints were wound healing, preventing major amputation and relief of rest pain.

Results:Major amputation was avoided in 26 patients, 21 patients $(72 \%)$ were relieved of rest pain. In 3 patients procedure was converted to open bypass. There were no cases of systemic complications and death during the follow-up period. Primary patency at 1 month was $72 \%$ and at 6 months $48 \%$.

Conclusion:Our data showed that endovascular intervention of infrapopliteal disease is an effective and safe treatment in patients with CLI, especially in those who are not fit for an open procedure.
\end{abstract}

Copy Right, IJAR, 2018,. All rights reserved.

\section{Introduction:-}

Peripheral arterial disease affects a major portion of our elderly population. Presentation vary from claudication pain ,rest pain to major or minor tissue loss. Main aim of intervention is to restore blood flow to the affected limb, thereby promoting wound healing and relief of rest pain. Sites of arterial involvement can be focal or multisegmental. Surgical intervention include open revascularisation or endovascular approach depending on the site of lesion and also taking into consideration patients co morbidities. As a major proportion of the elderly population have other associated risk factors like diabetes, hypetension, coronary artery disease, etc, endovascular approach has played a major role in reducing the morbidity and mortality rates. 


\section{Materials and methods:-}

This was a single centre retrospective observational study which analysed 29 patients with PAD involving the infrapopliteal segment, between January 2016- Jan 2018. A total number of 29 patients (21 men and 8 females; mean age 62 years, range 38-84) with CLI (class 4 to 6 according to Rutherford) were included. All the patients underwent tibial angioplasty targeted at single vessel or double vessel. The primary study endpoints were wound healing, relief of rest pain, avoiding major amputation of the target limb at 6 months and occurence of local and systemic complications specifically related to use of endovascular treatment.

\begin{tabular}{|l|l|}
\hline Characteristic & $\boldsymbol{n}(\boldsymbol{\%})$ \\
\hline Males & $21(72 \%)$ \\
\hline Females & $8(27 \%)$ \\
\hline Average age of presentation(years) & 62 years \\
\hline Presentation: & $20(68 \%)$ \\
Rest pain & $16(55 \%)$ \\
Major tissue loss & $5(17 \%)$ \\
Minor tissue loss & $4(13 \%)$ \\
Non healing stump & $18(62 \%)$ \\
\hline Type2 diabetes & $21(72 \%)$ \\
\hline Smoking/ tobacco consumer & \\
\hline Revascularisation: & $25(86 \%)$ \\
Single vessel & $4(13 \%)$ \\
Double vessel & Nil \\
All three vessels & \\
\hline Complication: & $2(6 \%)$ \\
Puncture related(hematoma) & $3(10 \%)$ \\
Dissection & 0 \\
Perforation & $6(20 \%)$ \\
Recoil & \\
\hline Outcomes: & $18(62 \%)$ \\
Palpable pulse/ABI improvement & $21(72 \%)$ \\
Wound healing/ relieved of rest pain & $3(10 \%)$ \\
Conversion to open bypass & $22(75 \%)$ \\
Amputation free survival at 6 months & $3(10 \%)$ \\
Major amputation & $4(13 \%)$ \\
Minor amputation & $21(72 \%)$ \\
\hline Primary patency rates: & $14(48 \%)$ \\
1 month & \\
6month & \\
\hline
\end{tabular}

\section{Results:-}

29 patients with infrapopliteal arterial involvement were evaluated. $72 \%$ of patients were male (21-male, 8 -female, M/F: 2.6/1). The mean age was 62 years at the time of diagnosis. About $62 \%$ of the patients were diabetics. The sex wise distribution and percentage of diabetics are given in figure 1 and 2 respectively. 


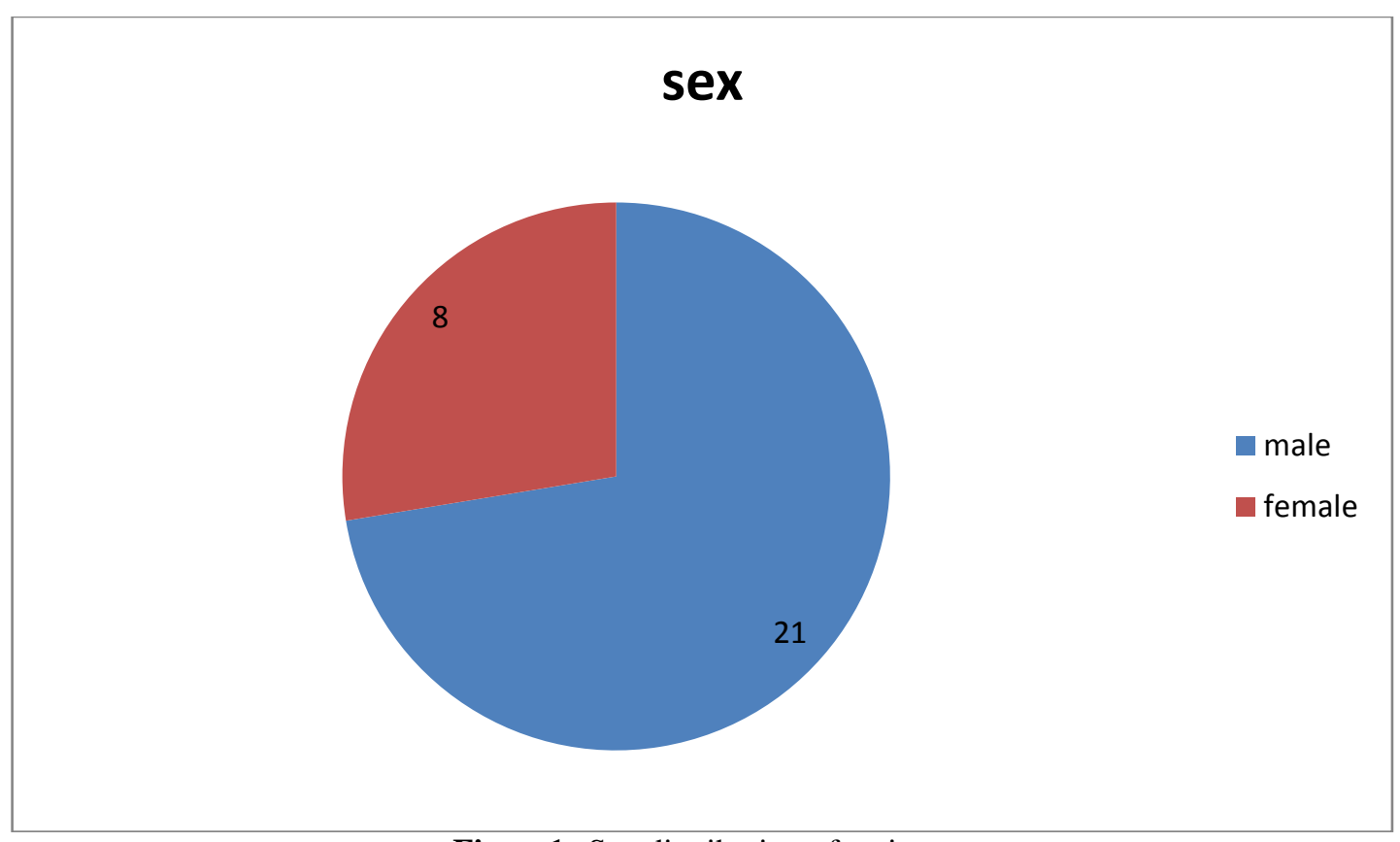

Figure1:-Sex distribution of patients

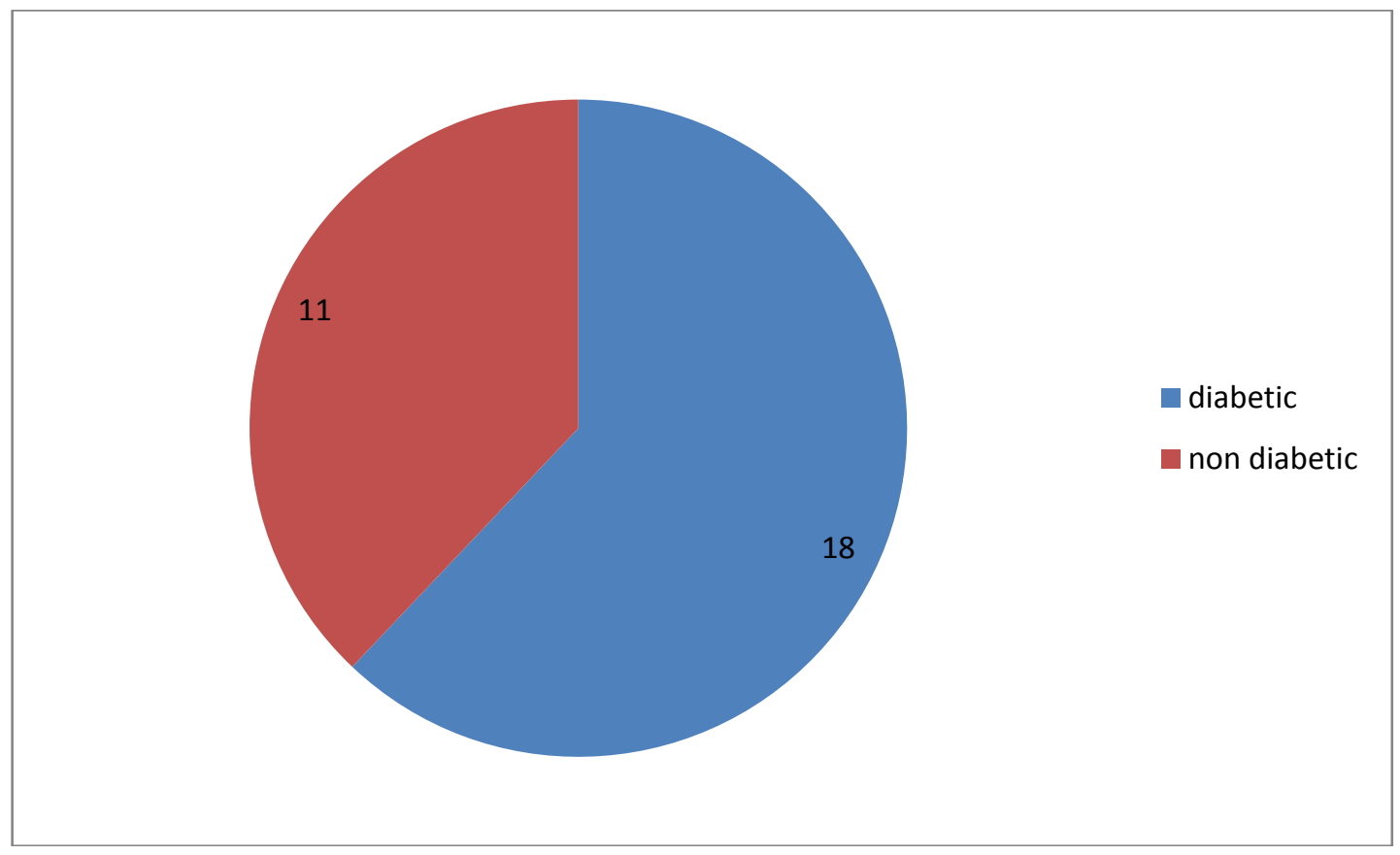

Figure 2:-Percentage of diabeticPatients mostly presented with rest pain(68\%) and tissue loss- major tissue loss( $55 \%)$, minor tissue loss (17\%) non healing stump (13\%) 


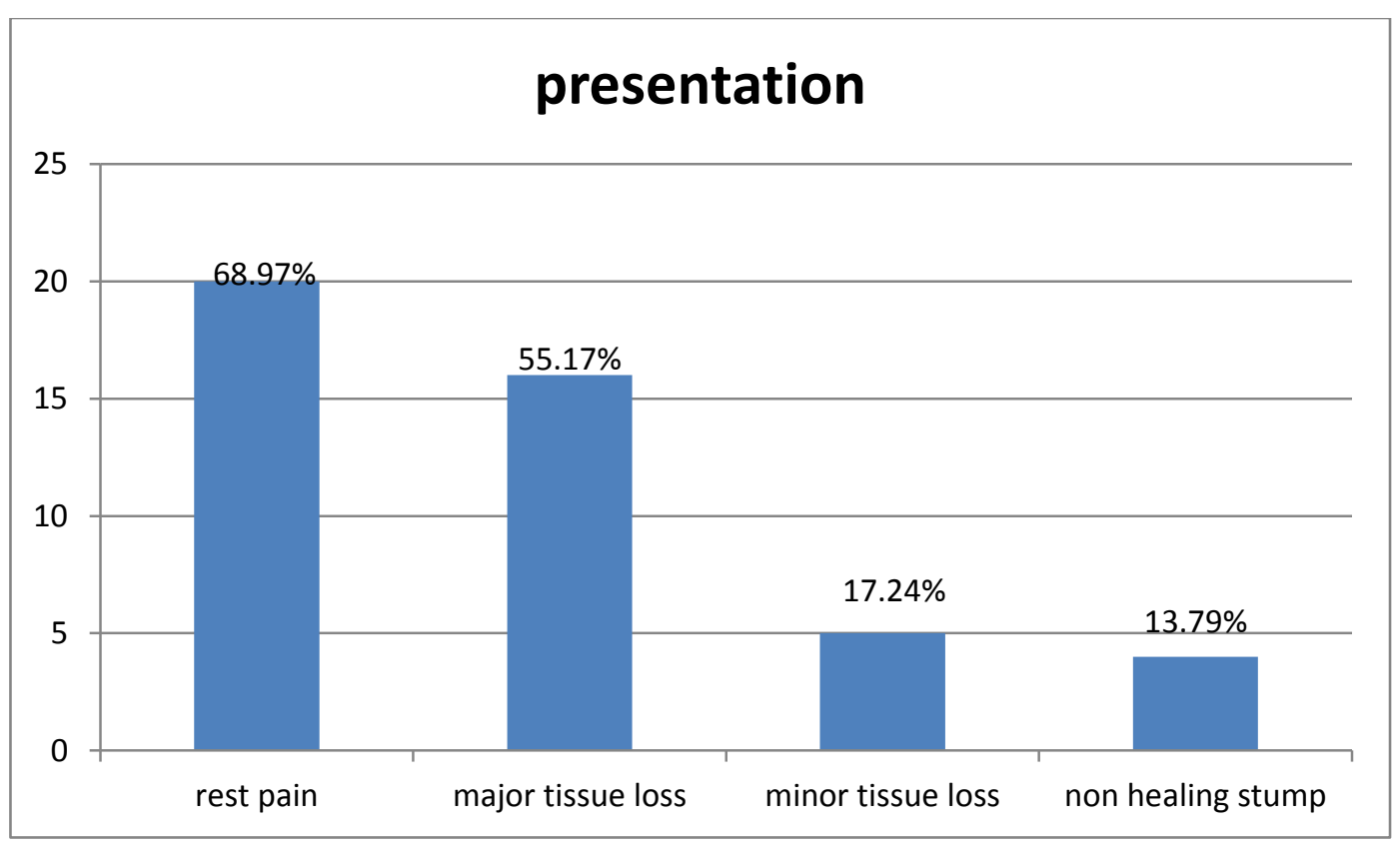

Figure 3:-PresentationOutcome was mainly evaluated by assessing the pulse status, rate of wound healing, conversion to open bypass procedure and amputation rates.

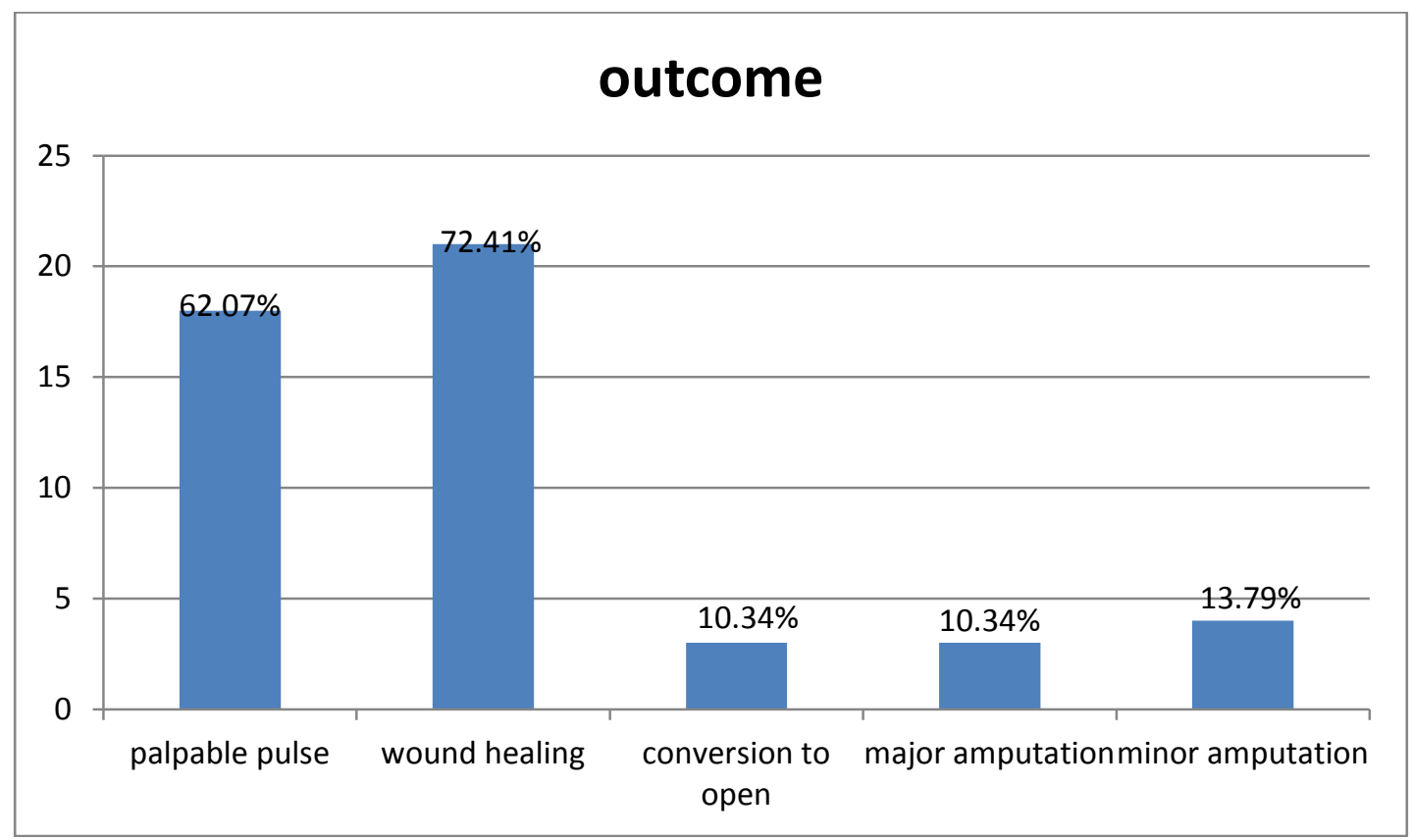

Figure 4: -OutcomeComplications included puncture site hematomain 2 patients (6.9\%), dissection was seen in 3 patients(10\%), recoil of the target vessel seen in 6 patients( $20 \%)$ 


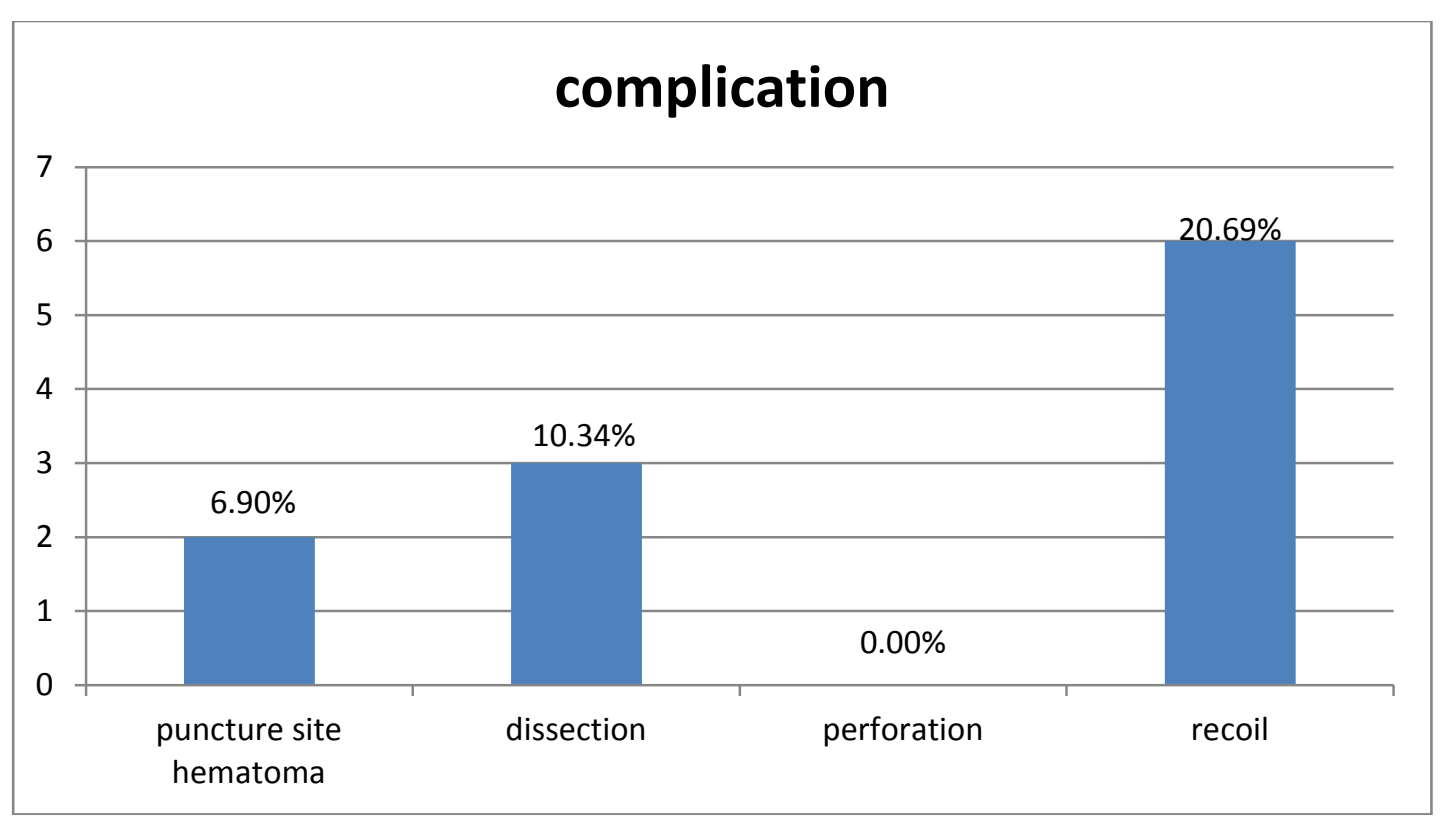

Figure 4:-ComplicationPatients were regularly followed in OPD and patency was assessed with doppler ultrasound. Primary patency rate at 1 month was $72 \%$ and at 6 months $48 \%$.

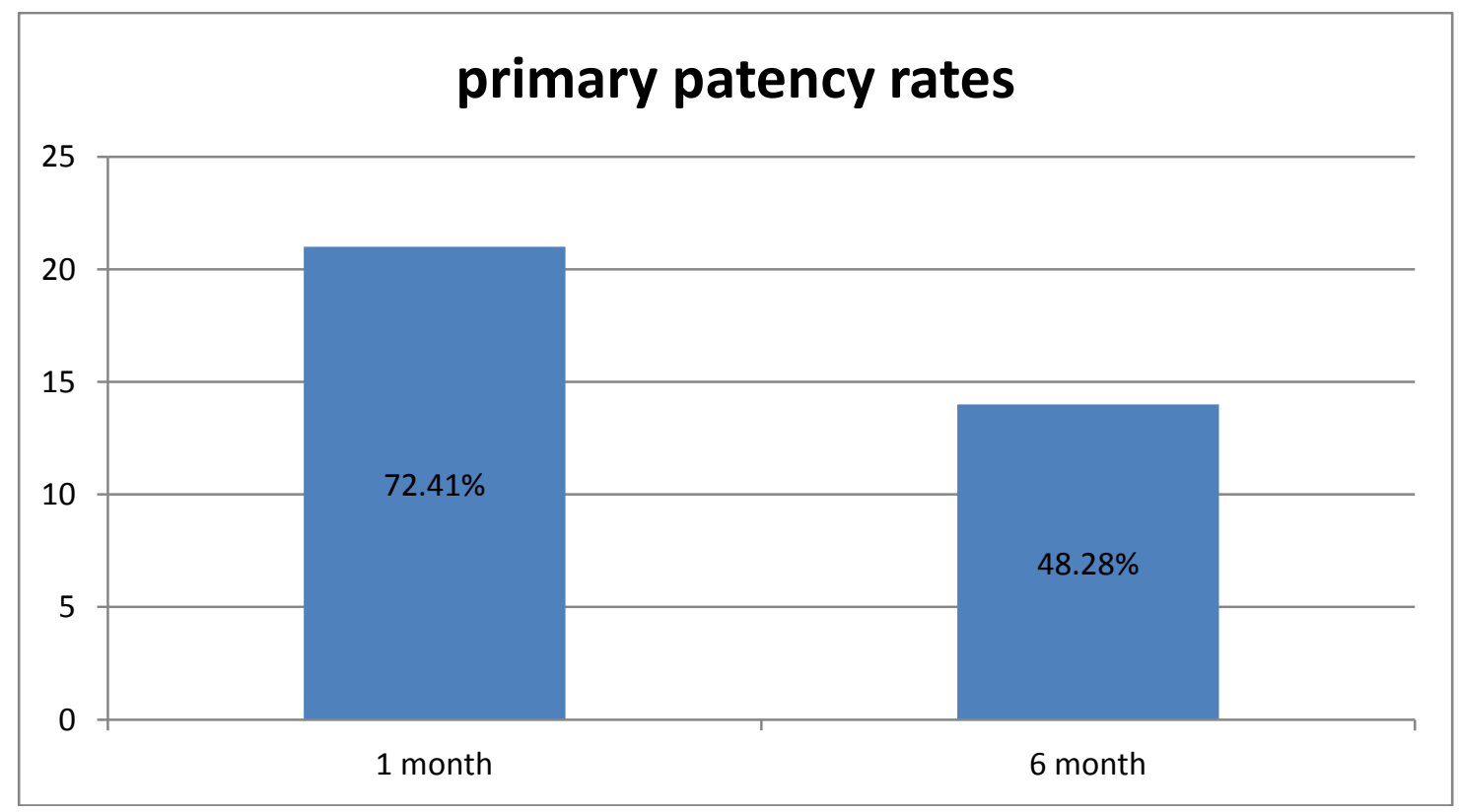

\section{Discussion:-}

The prevalence of lower extremity peripheral arterial diseasevaries with population, but is approximately 10 percent of adultsabove the age of 55 years. The clinical presentation is varied fromassymptomatic to intermittent claudication to limb threateningischemia .Management include medical interventions such assmoking cessation, antithrombotic and lipid lowering therapy,

diabetic and hypertension control. For those with significant ordisabling symptoms not responding to pharmacologic therapy andlifestyle adjustment intervention (percutaneous, surgical) is advised. 
The long-term effectiveness of percutaneous intervention isbased upon the length and site of the lesion. Short, focal stenosispresent with mild-to-moderate symptoms and respond well withintervetional therapies. Percutaneous intervention is also preferredin poor surgical candidates with more extensive PAD, or for limbsalvage before performing distal surgical bypass. Lesions withunfavorable anatomy such as long segment stenosis or occlusion,multifocal stenoses and eccentric calcified stenosis are associatedwith severe symptoms and will mostly require surgical intervention

Revascularisation options for symptomatic tibial artery disease include angioplasty alone, angioplasty with adjunctive stenting, or primary stenting. Primary stenting is preferred for calcific or long segment lesions. (1). Long term patency rate of percutaneous angioplasty for popliteal and tibial vessels are lower than PTA for aortoiliac disease. Smaller vessel diameter is the commonest cause for restenosis in the popliteal and infrapopliteal vessels. Other factors which negatively affect the long term patency include arterial occlusion, multiple vessel atherosclerotic disease, long or eccentric segment calcified lesion, poor distal run off and high Rutherford category. Below knee area is also prone to higher rates of restenosis, thrombosis and amputation in comparison to other vascular territories $(2,3)$.

Multiple studies have evaluated the outcomes of endovascularrevacularisation of infrapopliteal arterial occlusive disease and hasfound it comparable to bypass in terms of high limb preservationrates and lower risks of complications (4).A study by Mohapatra et all compared bypass vsendovascularapproach for tibial artery disease in patients with ischemic footulcers. It was found that at 6 months and 1 year follow up, theprimary patency in the endovascular group was found to be lowerthan the bypass group $(53.1 \%$ vs $38.2 \%)$ but the secondary patencywas similar and the wound healing was better in the endovasculargroup (29\%) compared to the bypass group(22.4\%). In hospitalcomplications including myocardial infarction and longer hospitalstay was found to be significantly more with the bypass group. It wasthus concluded that endovascular approach for tibial artery diseasewas a lower risk alternative to bypass with similar outcomes (5) .Similar study by Kaichung et all compared outcomes of endovascularrevascularisation versus venous bypass for tibioperoneal arterialocclusion and found that the amputation free survival for ER wassimilar to bypass but was associated with lower patency rate andhigher rates of reintervention (6) .Primary stenting is also an evolving option for infrapopliteadisease. It was found to reduce the risk of reinterventionandamputation, better wound healing, compared with plain balloonangioplasty with no negative impact on the mortality rates andRutherford class $(7,8)$. But issues of cost effectiveness, stent design,bare metal vs drug eluting stent are areas of debate and hencerequires further randomised control trails.

\section{Conclusion:-}

Our study showed that endovascular treatment of infrapopliteal disease is an effective and safe treatment in patients experiencing CLI, provides high limb preservation and low complication rates. Study outcomes support endovascular treatment as a primary option for patients experiencing CLI due to infra popliteal occlusive disease.

\section{Bibliography:-}

1. Acin F, de Haro J, Bleda S, Varela C, Esparza L. Primary nitinol stenting in femoropopliteal occlusive disease: a meta-analysis of randomized controlled trials. J EndovascTher Off J IntSoc

2. Endovasc Spec. 2012 Oct;19(5):585-95.

3. Fanelli F, Cannavale A. Endovascular treatment of infrapopliteal arteries: angioplasty vs stent in the drugeluting era. EurRadiol. 2014 Apr 1;24(4):793-8.

4. Matsi PJ, Manninen HI, Vanninen RL, Suhonen MT, Oksala I, Laakso M, et al. Femoropopliteal angioplasty in patients with claudication: primary and secondary patency in 140 limbs with 1-

5. year follow-up. Radiology. 1994 Jun;191(3):727-33.

6. Janko PJ, Nebojsa BB, Andrej PV. Endovascular Procedures in Treatment of Infrapopliteal Arterial Occlusive Disease: Single Center Experience With 69 Infrapopliteal Procedures. Arch Iran Med. 2018 Mar 1;21(3):11821.

7. Mohapatra A, Henry JC, Avgerinos ED, Boitet A, Chaer RA, Makaroun MS, et al. Bypass versus endovascular intervention for healing ischemic foot wounds secondary to tibial arterial disease. J Vasc Surg. 2018 Jul $1 ; 68(1): 168-75$.

8. Ye K, Shi H, Qin J, Yin M, Liu X, Li W, et al. Outcomes of endovascular recanalization versus autogenous venous bypass for thromboangiitisobliterans patients with critical limb ischemia due

9. totibioperoneal arterial occlusion. J Vasc Surg. 2017;66(4):1133-1142.e1. 
10. Fusaro M, Cassese S, Ndrepepa G, Tepe G, King L, Ott I, et al. Drug-eluting stents for revascularization of infrapopliteal arteries: updated meta-analysis of randomized trials. JACC CardiovascInterv. 2013 Dec;6(12):1284-93.

11. Katsanos K, Kitrou P, Spiliopoulos S, Diamantopoulos A, Karnabatidis D. Comparative Effectiveness of Plain Balloon Angioplasty, Bare Metal Stents, Drug-Coated Balloons, and Drug- Eluting Stents for the Treatment of Infrapopliteal Artery Disease: Systematic Review and Bayesian Network Meta-analysis of

12. Randomized Controlled Trials. J EndovascTher Off J IntSocEndovasc Spec. 2016;23(6):851-63. 